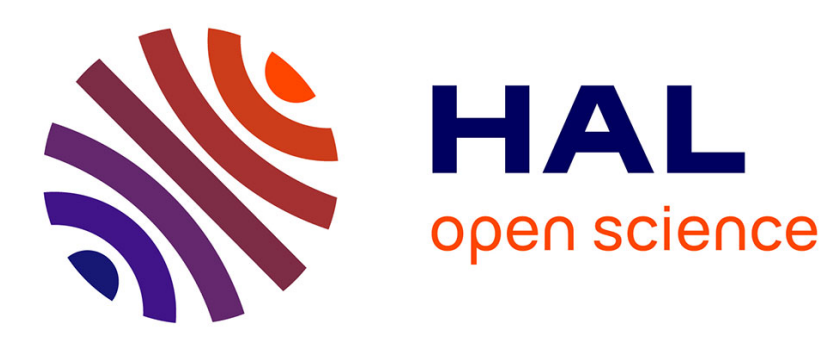

\title{
Optimization toward a high-average-brightness soft-x-ray laser pumped at grazing incidence
}

Kevin Cassou, Sophie Kazamias, D. Ros, Fabien Ple, Gérard Jamelot, Annie Klisnick, O. Lundh, F. Lindau, A. Persson, C.G Wahlstrom, et al.

\section{- To cite this version:}

Kevin Cassou, Sophie Kazamias, D. Ros, Fabien Ple, Gérard Jamelot, et al.. Optimization toward a high-average-brightness soft-x-ray laser pumped at grazing incidence. Optics Letters, 2007, 32 (2), pp.139-141. hal-00558023

\section{HAL Id: hal-00558023 \\ https://hal-iogs.archives-ouvertes.fr/hal-00558023}

Submitted on 27 Feb 2012

HAL is a multi-disciplinary open access archive for the deposit and dissemination of scientific research documents, whether they are published or not. The documents may come from teaching and research institutions in France or abroad, or from public or private research centers.
L'archive ouverte pluridisciplinaire HAL, est destinée au dépôt et à la diffusion de documents scientifiques de niveau recherche, publiés ou non, émanant des établissements d'enseignement et de recherche français ou étrangers, des laboratoires publics ou privés. 


\title{
Optimization toward a high-average-brightness soft-x-ray laser pumped at grazing incidence
}

\author{
K. Cassou, S. Kazamias, D. Ros, F. Plé, G. Jamelot, and A. Klisnick \\ LIXAM, UMR 8624, Université Paris Sud, F-91405 Orsay Cedex, France
}

O. Lundh, F. Lindau, A. Persson, and C.-G. Wahlström

Department of Physics, Lund University, S-22100 Lund, Sweden

S. de Rossi and D. Joyeux

Laboratoire Charles Fabry de l'institut d'Optique, Campus de Polytechnique-RD128, F-91127 Palaiseau, France

B. Zielbauer, D. Ursescu, and T. Kühl

Gesellschaft für Schwerionenforschung (GSI), D-64291 Darmstadt, Germany

Received August 21, 2006; revised October 10, 2006; accepted October 11, 2006; posted October 16, 2006 (Doc. ID 74292); published December 23, 2006

\begin{abstract}
We report the near-field imaging characterization of a $10 \mathrm{~Hz}$ Ni-like $18.9 \mathrm{~nm}$ molybdenum soft-x-ray laser pumped in a grazing incidence pumping (GRIP) geometry with a table-top laser driver. We investigate the effect of varying the GRIP angle on the spatial behavior of the soft-x-ray laser source. After multiparameter optimization, we were able to find conditions to generate routinely a high-repetition-rate soft-x-ray laser with an energy level of up to $3 \mu \mathrm{J} /$ pulse and to $6 \times 10^{17}$ photons $/ \mathrm{s} / \mathrm{mm}^{2} / \mathrm{mrad}^{2} /(0.1 \%$ bandwidth $)$ average brightness and $1 \times 10^{28}$ photons $/ \mathrm{s} / \mathrm{mm}^{2} / \mathrm{mrad}^{2} /(0.1 \%$ bandwidth $)$ peak brightness. (C) 2006 Optical Society of America

OCIS codes: $140.7240,340.7440$
\end{abstract}

In the development of coherent soft-x-ray sources, as a tool for chemistry, biology, and solid-state physics, plasma-based soft-x-ray lasers (SXRLs) are receiving an increased interest. A major advance has been made recently in significantly enhancing the pump efficiency and repetition rate of transient collisionally pumped SXRLs through the use of grazing incidence pumping (GRIP). ${ }^{1}$ Saturated SXRLs have been demonstrated down to $13 \mathrm{~nm}$ with subjoule laser pump energies $^{2,3}$ at $5-10 \mathrm{~Hz}$ repetition rates, ${ }^{4,5}$ while the shortest soft-x-ray laser wavelength driven into saturation is $5.9 \mathrm{~nm}$ when a low-repetition-rate, subkilojoules laser system is used. ${ }^{6}$ This progress allows the construction of compact SXRL beamlines at university-scale laboratories that can become alternatives to larger-scale facilities such as synchrotrons or free-electron lasers for some specific applications. The GRIP concept is a variation of the transient collisional pumping scheme in which a preformed plasma column is heated at near-normal incidence by a short laser pulse. In the GRIP scheme the short pulse beam is incident at grazing angle and refracted in the plasma [Fig. 1(a)]. The increased path length in the heated region leads to better energy deposition, hence better pumping efficiency. Further, the electron density at which the energy is absorbed can be controlled to the optimum pumping density by adjusting the GRIP angle, $\Phi$, following $n_{e, \text { abs }}=n_{c} \sin ^{2} \Phi$, where $n_{c}$ is the critical density. ${ }^{7}$ Most of the work until now has focused on the optimization of the SXRL beam intensity detected by an XUV spectrometer. Very little work has been done yet to investigate the effect of GRIP angle on the plasma itself and to characterize the SXRL source in terms of size and posi- tion. Such information is needed to provide benchmarks for numerical simulations and to improve the physical understanding of GRIP systems. Moreover, the control of the spatial characteristics of the source is crucial for applications, as it directly influences the main features of the SXRL beam.

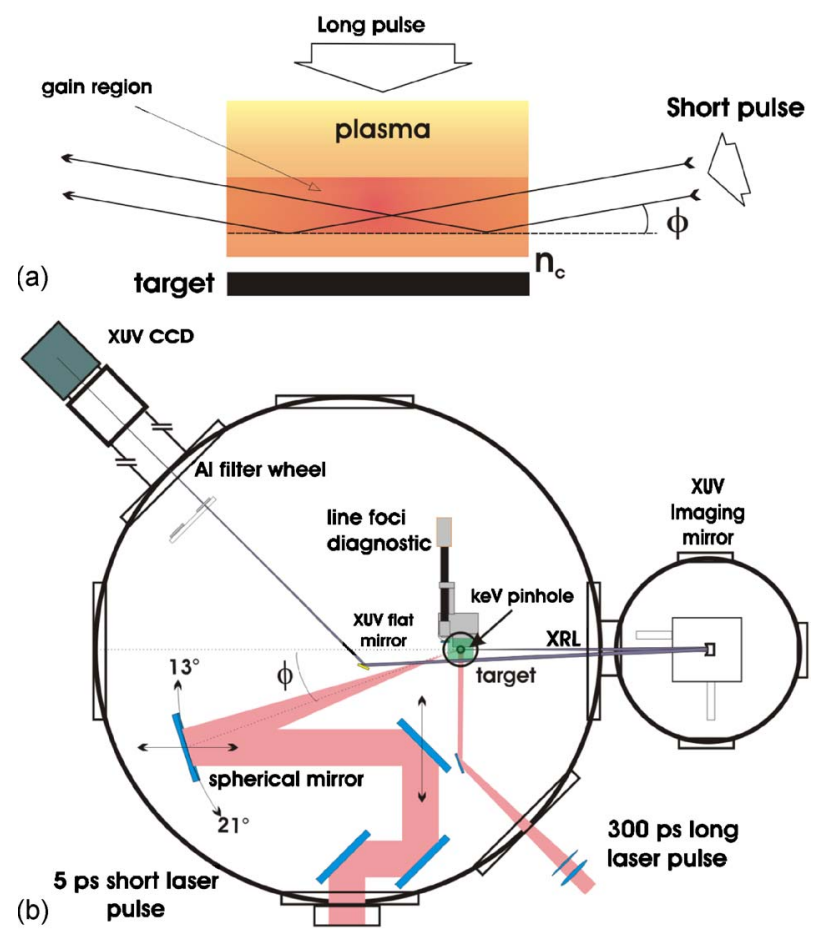

Fig. 1. (Color online) (a) Schematic view of the GRIP scheme. (b) Experimental setup showing the pump laser beamlines and SXRL diagnostics. 
In this Letter we report on a detailed characterization of a nickel-like molybdenum $\left(4 d^{1} S_{0}-4 p^{1} P_{1}\right)$ transient SXRL pumped in GRIP geometry, using a two-dimensional (2-D) high-spatial-resolution diagnostics imaging the SXRL at the output of the plasma rod. The position and energy distribution of the SXRL source were measured while optimizing the SXRL energy with respect to a set of parameters. At the optimum GRIP angle, found to be $19^{\circ}$, the gain region is the closest to the target surface. A maximum integrated output energy of $3 \mu \mathrm{J} /$ pulse was routinely obtained at $10 \mathrm{~Hz}$, corresponding to an average power of $30 \mu \mathrm{W}$. In addition, we found that the SXRL source size and shape can be controlled and optimized by adjusting the delay and level of a lowenergy prepulse. In this way, we were able to decrease the source diameter to $\sim 10 \mu \mathrm{m}$ FWHM, yielding a nearly complete spatially coherent SXRL source with an output fluence of $1 \mathrm{~J} \mathrm{~cm}^{-2}$.

The experiment was performed at the Lund Laser Centre, Sweden, using a chirped-pulse amplification Ti:sapphire laser operating at $10 \mathrm{~Hz}$. The $1.4 \mathrm{~J}$, 300 ps chirped-pulse beam available after the final amplification stage was split into an uncompressed long pulse (LP), which created a plasma, and a short pulse (SP), partly compressed to $5 \mathrm{ps}$, which heated the plasma and generates the SXRL emission. The splitting ratio between the LP and the SP was variable and was adjusted for optimum x-ray output. In the rest of the study, the LP delivered $480 \mathrm{~mJ}$ and the SP delivered $500 \mathrm{~mJ}$ on target. A prepulse (PP) generator was inserted in the LP beamline to provide an additional low-energy PP. For most of the experiment, the PP preceded the LP by $1.3 \mathrm{~ns}$ and contained 7\% of its energy. All three pulses irradiated a $4 \mathrm{~mm}$ long Mo slab target, as shown in Fig. 1(b). The $300 \mathrm{ps}$ LP and PP beams were focused into a $70 \mu \mathrm{m}$ $\times 5 \mathrm{~mm}$ FWHM line focus with a combination of a spherical lens $(f=1 \mathrm{~m})$ and a cylindrical lens $(f=$ $-4 \mathrm{~m}$ ), yielding irradiances of $3.8 \times 10^{11} \mathrm{~W} \mathrm{~cm}^{-2}$ and $\sim 5 \times 10^{10} \mathrm{~W} \mathrm{~cm}^{-2}$, respectively. The SP beam was focused into a line of $40 \mu \mathrm{m}$ FWHM in width, with a $f$ $=650 \mathrm{~mm}$ spherical mirror onto the target at a grazing angle, adjustable under vacuum from $13^{\circ}$ to $21^{\circ}$ [Fig. 1(a)]. The length of the line focus, which depends on the beam diameter and grazing angle, varied from $5 \mathrm{~mm}$ for $13^{\circ}$ to $9 \mathrm{~mm}$ for $21^{\circ}$. This focusing configuration induced an intrinsic traveling wave with a velocity close to the speed of light (within less than 5\% deviation). The superposition of the LP and $\mathrm{SP}$ at the target plane was controlled with an imaging microscope device, with a resolution of about $3 \mu \mathrm{m}$. In contrast with previous work, ${ }^{2}$ we vary the GRIP angle $\Phi$ by tilting and translating the SP beam mirrors, instead of the target. This condition was found to be important to get a constant line focus quality and to allow the implementation of highspatial-resolution diagnostics of the SXRL plasma. The diagnostics, shown in Fig. 1(b), consisted of a 2-D XUV near-field imaging system. This diagnostic consisted of a $1 \mathrm{~m}$ radius-of-curvature spherical multilayer mirror used at $0.7^{\circ}$ from normal inci- dence. After redirection by a flat multilayer mirror, the image was detected on a 16-bit back thinned XUV charge-coupled device camera placed $4.28 \mathrm{~m}$ from the imaging mirror, yielding a magnification of 7.6. The resolution was $1.7 \mu \mathrm{m}$, limited by the $13 \mu \mathrm{m}$ pixel size. A set of 1 to $6 \mu \mathrm{m}$ thick aluminum filters was used to adjust the signal level. Figure 2 shows the effect of varying the GRIP angle. At $19^{\circ}$ the mean fluence in the SXRL source aperture exhibits a clear optimum of $0.33 \mathrm{~J} \mathrm{~cm}^{-2}$, corresponding to an integrated energy of $3 \mu \mathrm{J}$. We assume for the estimation of SXRL energy that Al foil absorption is given by Henke tables, ${ }^{9}$ and we consider a $7.5 \mathrm{~nm}$ thick oxide layer on each side of the $\mathrm{Al}$ filter foil. Also plotted in Fig. 2 is the position of the SXRL source relative to the target surface. The position of the SXRL source moves toward the target surface when the GRIP angle is increased from $15^{\circ}(60 \mu \mathrm{m})$ to $19^{\circ}(35 \mu \mathrm{m})$. This trend is expected as the pump laser beam penetrates deeper into the plasma and is absorbed at a higher electron density for increasing GRIP angle. Above that angle, the SXRL source aperture is shifted to larger distances. This can be interpreted as a result of steeper density gradient in the absorption region, leading to enhanced refraction of the SXRL beam. From Fig. 2, $\Phi=19^{\circ}$, the GRIP angle clearly corresponds to the optimum angle with regard to SXRL output and gives the smallest distance between source and target surface. At the optimum angle the electron density corresponding to the perigee point is $n_{e} \approx 1.8 \times 10^{20} \mathrm{~cm}^{-3}$. Accordingly, optimization of the SXRL output with regard to grazing angle appears to be a balance between absorption at high-electron-density and low-electron-density gradients.

Figure 3 shows the behavior of the SXRL source at the optimum GRIP angle of $19^{\circ}$ as a function of the LP-SP delay (peak to peak). While the horizontal (target normal) width does not vary significantly, the vertical width is observed to strongly increase with the LP-SP delay up to $400 \mathrm{ps,}$, where it reaches the line focus width of the SP, and remains approxi-

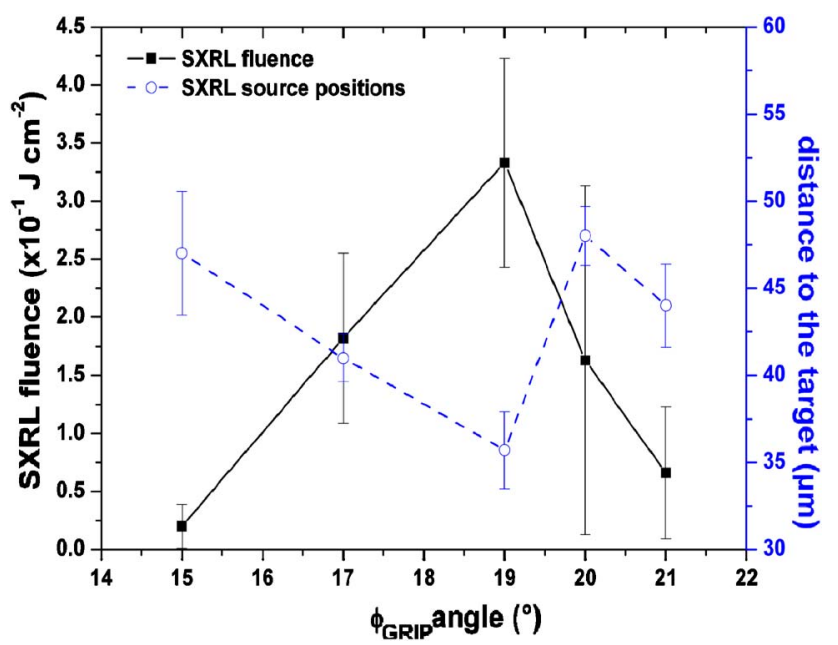

Fig. 2. (Color online) Mean SXRL fluence (solid curve), distance to the target surface of the emission peak of the SXRL (dashed curve). Each data point is an average over 10 to 20 shots. 


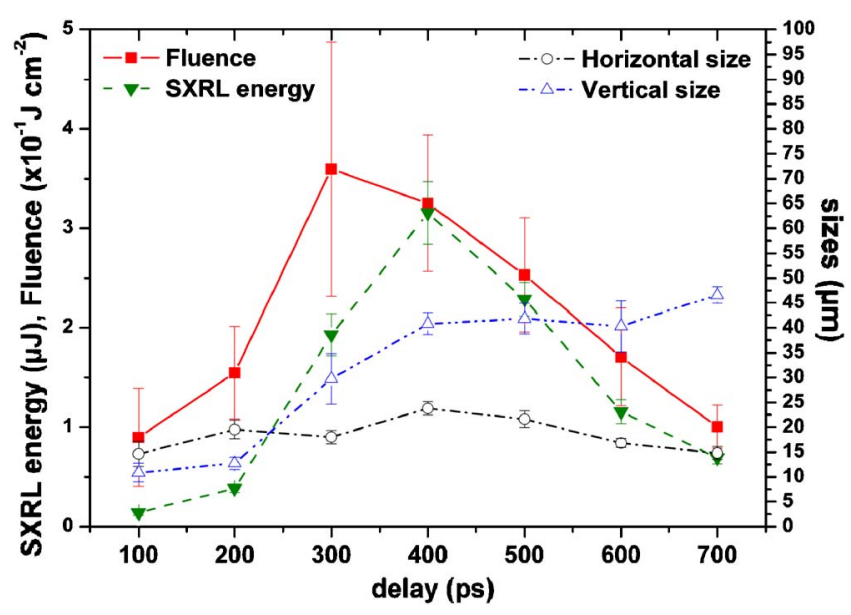

Fig. 3. (Color online) LP-SP delay effect at $\Phi=19^{\circ}$. Left scale, integrated energy and mean fluence, right scale, SXRL FWHM vertical and horizontal widths.
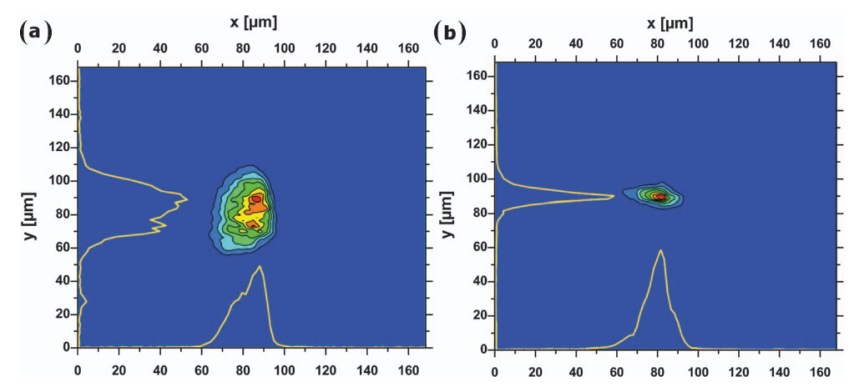

Fig. 4. Near field images, $\Phi=19^{\circ}$ : (a) PP-LP delay, $1.3 \mathrm{~ns}$; (b) doubled energy in the PP and PP-LP delay, $2.4 \mathrm{~ns}$.

mately constant for longer delays. As a result, the SXRL integrated energy peaks at $400 \mathrm{ps}$, while the mean fluence is maximum for a shorter delay of $300 \mathrm{ps}$. The behavior of the vertical width can be attributed to the lateral expansion of the plasma in the region where the short pulse is absorbed. At optimal conditions, we find that the SXRL is operated in the onset of saturation regime, with a measured gain coefficient of $g \sim 45 \mathrm{~cm}^{-1}$. Finally, Fig. 4 illustrates the influence of the low energy prepulse on the size and shape of the SXRL source. The reference case is shown in Fig. 4(a) and corresponds to the maximum output energy of $3 \mu \mathrm{J}$ at $19^{\circ} \mathrm{GRIP}$ angle. The energy distribution in the SXRL near field is relatively smooth with a $21 \mu \mathrm{m} \times 42 \mu \mathrm{m}$ FWHM size. Figure 4(b) shows the dramatic effect of varying the PP-LP delay from 1.3 to $2.4 \mathrm{~ns}$ and doubling the PP energy level. This leads to a very small, nearly circular, source of $\sim 10 \mu \mathrm{m}$ FWHM in diameter, containing $1 \mu \mathrm{J}$ and reaching a mean fluence close to $1 \mathrm{~J} \mathrm{~cm}^{-2}$. The maximum theoretical transverse coherence length at the exit aperture ${ }^{8}$ is estimated to $8 \mu \mathrm{m}$, considering the amplifier geometry. It leads to a transverse coherence length similar to the size of the SXRL source. This result, which needs further inves- tigation, was obtained in a reproducible way with a similar source size over a wide LP-SP delay range. Figure 4 hence demonstrates the relevance of the near-field imaging diagnostic to performing SXRL optimization.

In conclusion, we present an extensive multiparameter optimization of a transient Ni-like Mo soft$\mathrm{x}$-ray laser at $18.9 \mathrm{~nm}$, pumped under grazing incidence. By imaging the SXRL at the output of the plasma rod, we obtain, for the first time to our knowledge, a detailed insight into the effect of varying the GRIP angle among other parameters. At optimal conditions we demonstrate $10 \mathrm{~Hz}$ operation with a maximum mean energy of $3 \mu \mathrm{J}$ per pulse, corresponding to both high pumping efficiency $\left(3 \times 10^{-6}\right)$ and average power of $30 \mu \mathrm{W}$. By adjusting the low-energy prepulse, we obtain the smallest source with nearly complete spatial coherence and high mean fluence of $1 \mathrm{~J} \mathrm{~cm}^{-2}$. Assuming a reasonable value for the pulse duration $(\approx 5 \mathrm{ps}){ }^{8}$ we estimate the average brightness to be $6 \times 10^{17}$ photons $/ \mathrm{s} / \mathrm{mm}^{2} / \mathrm{mrad}^{2} /(0.1 \%$ bandwidth) and the peak brightness to be 1 $\times 10^{28}$ photons $/ \mathrm{s} / \mathrm{mm}^{2} / \mathrm{mrad}^{2} /(0.1 \% \quad$ bandwidth $)$, which compares well with third-generation synchrotron sources and, if we take in account the spectral bandwidth $\left(\sim 10^{-5}\right)$, also to free-electron laser sources.

This work was supported by the Swedish Research Council, the Knut and Alice Wallenberg Foundation, and EU Access to Research Infrastructures activity (contract RII3-CT-2003-506350, Laserlab Europe). K. Cassou's e-mail address is kevin.cassou@lixam.upsud.fr.

\section{References}

1. R. Keenan, J. Dunn, P. K. Patel, D. F. Price, R. F. Smith, and V. N. Shlyaptsev, Phys. Rev. Lett. 94, 103901 (2005).

2. B. M. Luther, Y. Wang, M. A. Larotonda, D. Alessi, M. Berrill, M. C. Marconi, and J. J. Rocca, Opt. Lett. 30, 165 (2005).

3. Y. Wang, M. A. Larotonda, B. M. Luther, D. Alessi, M. Berril, V. N. Shlyaptsev, and J. J. Rocca, Phys. Rev. A 72, 053807 (2005).

4. A. Weith, M. A. Larotonda, Y. Wang, B. M. Luther, D. Alessi, M. C. Marconi, and J. J. Rocca, Opt. Lett. 31, 1994 (2006).

5. J. Tümmler, K. A. Janulewicz, G. Priebe, and P. V. Nickles, Phys. Rev. E 72, 037401 (2005).

6. R. Smith, G. J. Tallents, J. Zhang, G. Eker, S. McCabe, G. J. Pert, and E. Wolfrum, Phys. Rev. A 59, R47 (1999).

7. G. J. Pert, Phys. Rev. A 73, 033809 (2006).

8. O. Guilbaud, A. Klisnick, K. Cassou, S. Kazamias, D. Ros, G. Jamelot, D. Joyeux, and D. Phalippou, Europhys. Lett. 74, 823 (2006).

9. B. L. Henke, E. M. Gullikson, and J. C. Davis, At. Data Nucl. Data Tables 54, 181 (1993). 